Secondly, an even more integrated approach between disciplines is required to develop a coherent view of the oceans which can be related to other studies of the total environment. As J.H. Steele, the present director at Woods Hole, writes in the final chapter, "Earth Sciences" must become the broad conceptual unit within which oceanographers, geochemists, meteorologists etc. approach the practical problems of the future; in this context the role of big institutions is vital, both in leading the way and in providing facilities for outside people to participate in research. And thirdly, there is wide agreement that the oceanic environment needs protection now. There is good evidence that human impact on the oceans represents a "global geochemical experiment" with unknown consequences (p.305), and equally worrying are the various shoreline problems typified by the New Jersey beach scene (p.98). More optimistically, however, the fishery and aquaculture experts give considerable hope for better manipulation and exploitation of biological resources provided pollution is controlled.

Apart from the upside down satellite image of the Gulf of Maine (p.70), the production of the book is excellent. It should be read by both oceanographers and earth scientists.

P.M. Holligan is at the Marine Biological Association, Plymouth.

\section{Animals and plants}

\section{J.B. Whittaker}

\section{Herbivory: The Dynamics of Animal- Plant Interactions. \\ By Michael J. Crawley. \\ Blackwell Scientific/University of California Press: 1983. Pp.437. \\ £27.50, \$45.}

PREDATORS have enjoyed much more attention from textbook writers than have herbivores, perhaps because it is easier for a single author to appreciate interactions within a kingdom than between animals and plants. It was also easier to model the dynamics of animal-animal interactions, at least until the breakthrough of Harper's Population Biology of Plants, published by Academic Press in 1977. Up to then, investigators of the three groups concerned in herbivory - vertebrate herbivores, invertebrate (mainly insect) herbivores and plants - had largely gone their respective ways; such grazing experiments as were conducted were usually confined to large, easily excluded vertebrates, while studies of invertebrate herbivory, led by entomologists, tended more towards explaining how plants affect animal feeding and dynamics than vice versa.

Bringing together these viewpoints and attempting a balanced synthesis is a formidable task. Dr Crawley has chosen to tackle it by emphasizing the dynamics of interactions between species in three ways: by first showing us how plants might be affected by grazing animals; by next discussing the extent to which the dynamics of herbivore populations might be determined by their food and the problems of

\section{New in paperback}

DAviD Bohm's Wholeness and the Implicate Order (reviewed by Abner Shimony in Nature 291,435 ; 1981) has recently appeared in paperback. Publisher is Ark Paperbacks, an imprint of Routledge \& Kegan Paul; price is $£ 2.95, \$ 6.95$. obtaining it; and, thirdly, by bringing together these two themes, mainly in the form of population models. The last section of the book deals with community dynamics.

Within this framework, this is a stimulating book which follows the fashionable approach of dealing with ecological principles and processes in terms of generalized hypotheses supported by selected references (about 1,000 in this case, though with a few curious omissions of recent important work and of some older yet still pertinent reviews). All this has been fused into approximately 350 pages of ideas and information which cover an extremely wide array of subject matter. The technique used is one of illustrating a rapid and vigorous flow of ideas with brief descriptions of original studies. The drawback is that this sometimes reads like a series of abstracts which tells us little about the organisms themselves. I jotted down a list of over a dozen well-known, critical studies of herbivores which were together referred to in a total of five pages, in only one case with any continuity of discussion.

Valuable as they are, syntheses from hundreds of references cannot provide a complete substitute for detailed case studies which are the real starting point for so many of the ideas so enthusiastically discussed. For this, perhaps idiosyncratic, reason, I would recommend the book to experienced workers as an essential and comprehensive review. But for undergraduates, to whom syntheses of ecological information can seem beguilingly simple, I would caution the need for more direction towards substantial field studies which alone can put theories into perspective by showing how general principles may interrelate in the dynamics of one system. All readers, however, should find the summary chapter most useful and thoughtprovoking even if, as the author suggests and I agree, they will not necessarily concur with all the conclusions.

J.B. Whittaker is Head of the Department of Biological Sciences at the University of Lancaster.

\section{Agents of change}

\section{Tease}

Aneuploidy. By D.J. Bond and

Ann C. Chandley.

Oxford University Press: 1983. Pp.200. $£ 25, \$ 69$.

DELIBERATE or accidental exposure to radiation, chemicals and drugs is commonplace in the human population and concern has been expressed that some at least of these agents may increase the risk of chromosomal imbalance (aneuploidy) in subsequent generations. This possibility stimulated great interest both in the mechanisms causing aneuploidy and in experimental approaches to characterization of the effects of suspect agents.

Bond and Chandley's review of aneuploidy examines the current understanding of these topics. With regard to human aneuploidy, they discuss, for example, the importance and possible causes of the maternal age effect and describe relative chromosome involvement in spontaneous aneuploidy as determined from abortuses. More usefully, the various suggested mechanisms leading to aneuploidy, ranging from the obvious (non-disjunction) to the more speculative (extra replication of chromosomes), are discussed fully in the light of experimental results. It is salutary to be reminded that the relative contribution of each putative mechanism to spontaneous aneuploidy has not yet been determined.

A substantial portion of the review is given over to summaries of results from experiments on the effects of physical and chemical agents inducing aneuploidy in a diverse array of test organisms. Radiation exposure has been shown to induce aneuploidy in a number of species. The larger part of the data derives from Drosophila reflecting the long interest in radiation effects in this species. The causes of radiation-induced aneuploidy have yet to be unequivocally determined although much evidence has been accumulated to favour the view that it is the result of the induction of chromosome interchanges. Chemical agents have not been studied to the same extent as radiation. The observation that certain compounds show conflicting behaviour with regard to aneuploidy induction in lower and higher eukaryotes is disappointing given the relative ease of using such lower eukaryotes as fungi in screening programmes.

Overall, Bond and Chandley have provided a thorough yet concise synthesis of approaches to aneuploidy. Their book will be of great value to those engaged in such research and should prove of interest to anyone concerned with aneuploidy in the human population.

C. Tease is at the MRC Radiobiology Unit, Harwell, Oxfordshire. 